\title{
Tourists' use of Airbnb app for visiting a historical city
}

\author{
Robert Jeyakumar Nathan $^{1}$ (D) Vijay Victor $^{2}$ (D) Melanie $\operatorname{Tan}^{1}$ (D) \\ Maria Fekete-Farkas ${ }^{3}$ (D)
}

Received: 10 July 2019 / Revised: 9 April 2020 / Accepted: 11 April 2020 / Published online: 20 April 2020 (c) The Author(s) 2020

\begin{abstract}
Airbnb is a home-sharing mobile platform that enables tourists and local hosts to connect. Airbnb mobile app allows hosts to list down the space available for rent and allow tourists to look for accommodations that are often more localized. Historical cities are often engaging tourists using traditional hotel reservation methods such as phone reservations or booking by travel agents, however, given digital disruption more local businesses are adopting technology in their business. This motivated the current study to assess the rate of peer-to-peer technology pervasiveness in historical city tourism, particularly for hotel booking using Airbnb app. This research investigates the factors that predict tourists' behavioural intention to use Airbnb app when they travel to the historical city of Malacca in Malaysia by adopting the Extended Unified Theory of Acceptance and Use of Technology (UTAUT2) model and by critically evaluating the exhaustiveness of the theory to measure tourists' use of a mobile app. Partial Least Square analysis was used to test the research model, construct path model and to validate research hypotheses. The results from a sample of 200 tourists who visited and stayed in Malacca show that price value and social influence have high significant positive influence on their behavioural intention to use Airbnb app when booking accommodation in the historical city. In contrast, hedonic motivation and habit were found not significant, potentially due to the short-term and occasion-specific usage of Airbnb app not forming enjoyment in the process of usage, which raises concerns on applicability and relevance of UTAUT2 theory to measure user adoption of a mobile app for tourism. A peculiar finding in the study is the significant negative influence of facilitating condition to behavioural intention, for which we explain a plausible cause in the paper.
\end{abstract}

Keywords Airbnb $\cdot$ Mobile app $\cdot$ Malacca $\cdot$ Historical city tourism $\cdot$ Peer to peer

Maria Fekete-Farkas

Farkasne.Fekete.Maria@gtk.szie.hu

Extended author information available on the last page of the article 


\section{Introduction}

Platform-based mobile device apps are flourishing as they bring solutions to people at their fingertips. Also known as Peer-to-Peer (P2P) economy, mobile apps solutions are a growing trend and liked by the masses (Bardhi and Eckhardt 2012). The online P2P platforms have a significant impact on several marketing and consumer industries, in particular, the transportation and tourism industries (Pizam 2014). Among the notable players in these industries are Uber, Grabcar, and Airbnb.

Tourism is a booming industry in South East Asia and Malaysia is among the highest receiver of tourists in the region. The tourism industry plays a major role in the environmental, societal and economic planning of the Malaysian government (Amir et al. 2015). Tourism is the second largest contributor to Malaysia's GDP growth (Teo et al. 2014). Hence, the Malaysian government has taken various initiatives in promoting tourism in the country which includes the adoption of technology to empower local business owners to promote as well as to digitally manage their businesses. Among the 13 states in Malaysia, the State of Malacca is recognised as the historical entrance to Malaysia and is recognised as a World Heritage City by UNESCO.

With the idea of sharing economy becoming popular, consumers now have a range of affordable options to choose from. One such platform is Airbnb, which is fast-growing since it was incorporated in August 2008. Airbnb is positioned as a home-sharing $\mathrm{P} 2 \mathrm{P}$ online platform that allows tourists and local hosts to connect. In other words, Airbnb is an online platform that connects individuals who are looking for accommodations and people who want to rent out their homes. It operates in the consumer-to-consumer $(\mathrm{C} 2 \mathrm{C})$ business model sphere contrary to the traditional online hotel booking websites which are often business-to-consumer (B2C) in nature (Yoon 2017).

It is a disruptive digital innovation that has threatened the conventional hotel industry as more and more tourists have chosen Airbnb instead of hotels in recent years (Guttentag 2015; Tham 2016). Airbnb acts as an alternative for temporary accommodations for tourists and it is posited to affect the revenue growth of the hotel industry (Byers et al. 2016). Airbnb and its impact on the economy is progressively being studied (Perez-Sanchez et al. 2018). To date, Airbnb has over three million listings worldwide, it interfaces individuals to special vacation experiences in at least 65,000 cities and 191 countries and has served over 200 million guests all around the world in less than 10 years of its inception. As of November 2018, the number of listings in Malaysia stood at 44,000 which marked a year on year growth rate of nearly $60 \%$. The number of active Airbnb listings in Malacca city as of February 2018 was 1350 (Rent and Returns 2018).

With the digital disruption in the tourism sector, historical cities like Malacca would be faced with new challenges and opportunities to capitalise on P2P mobile apps to boost its tourism. The amalgamation of a modern tourist's tool such as the Airbnb app and heritage home owners who are renting out their properties in a historical city, it is worth investigating the role of $\mathrm{P} 2 \mathrm{P}$ technology in empowering tourism, which primarily motivated this study. 
Against this backdrop, this study aims to investigate the adequacy of UTAUT2 theory in predicting tourists' intentions to use Airbnb app when booking lodging during their stay at the historical city of Malacca. The UTAUT2 theory has been critically applied in various technology adoption context, albeit the application of its usage to predict tourists' intention to use a mobile P2P App such as the Airbnb for visiting a historical city is new. Moreover, considering the growing significance of Airbnb, it is useful to investigate the extent to which the app is popular among the visitors to a historical city that previously had less digital technology embedded into its tourism ecosystem, yet now poised to embrace digital technologies for tourism. This research adopts the "Extended Unified Theory of Acceptance and Use of Technology" (UTAUT2) model as an overarching theory to measure tourists' behavioural intentions to use the Airbnb app for booking their stay while visiting the historical city of Malacca.

\section{Literature review}

\subsection{Historical city as a context of study}

Malaysia has 13 states and Malacca is the oldest state in the country. On the 7th of July 2008, The Malacca state was formally recognized as a World Heritage Site (WHS) by UNESCO and garnered its popularity among visitors as a historical city (Teo et al. 2014). To further emphasize the role of Malacca in Malaysian Tourism, the state government published a book in 2001 entitled "Malacca Historic Tourism: Visit Historic Malacca Means Visit Malaysia", which positioned Malacca as the entry state for tourist entering Malaysia. In 2016, 12.74 million tourists visited Malacca, while in 2017, 16.7 million visited Malacca, a growth of $31 \%$ in a year (The Star Online 2018). The increase in tourism activity in Malacca has benefited the local communities and the overall economy of the state and country, as well as increased the academic interests in looking at the hotel industry quality and performance in Malacca (Goh et al. 2012). Foo and Krishnapillai (2018) and See and Goh (2018) have also highlighted the benefits accrued to the local economy and the tourism sector in Malaysia when the sister-town of Malacca from Penang, the city of George Town was listed as a World Heritage Site.

Mutal (2011) defines historical cities as "active human settlements strongly conditioned by a physical structure originating in the past and recognizable as representing the evolution of its people". Historical cities provide for cultural tourism and they offer many opportunities for the economic rejuvenation of the local cities. However, it requires efficiently tailor-made innovative and creative frameworks to utilize the limited resources as a source of revenue and most importantly to shield the sites from the ill effects of tourismification (Jansen-Verbeke 1998). An area that requires such strategic intervention is the issue of lodging in historical cities (Lee and Chhabra 2015). Exorbitant prices are often charged by boutique hotels in historical cities which made trips very expensive for tourists (Caserta and Russo 2002). With digital disruption and P2P mobile apps, the lodgings are made more affordable 
and transparent, however, there is still a dearth of empirical studies on consumer preferences to use mobile apps for booking lodging in historical cities.

Among the dominant models used in the previous studies to examine behavioural intentions of users to adopt a particular technology is the "Extended Unified Theory of Acceptance and Use of Technology" (UTAUT2) model. Min and Lu (2017) analysed tourists' intentions to use Airbnb in China using the UTAUT2 model. The result of the study identified factors including performance expectancy, social influence, hedonic motivation and price value as significant factors that influence the tourists' intentions to use Airbnb in China. The study did not specifically examine the context of a historical destination. The results also showed that cross cultural experience was a significant moderator in the relationship between performance expectancy and behavioural intention.

Gupta and Dogra (2017) used UTAUT2 to examine factors affecting tourists' intentions to use mapping apps while travelling. The authors identified habit, facilitating conditions, performance expectancy, and hedonic motivations as significant antecedents of behavioural intentions to use mapping apps. Although both studies above Min and Lu (2017) and Gupta and Dogra (2017) examined the adoption of an App using UTAUT2 model, they arrived at only two similar significant factors (performance expectancy and hedonic motivation) while highlighting different sets of factors that predicted user intentions and actions in both contexts. This provides for a context-specificity for UTAUT2 model, hence need to be studied within a usercontext or destination-context in order to minimalize the theory, and explain tourists behaviour more parsimoniously. Similarly, in another related study, Antunes and Amaro (2016) used UTAUT2 and identified factors that influenced intentions of pilgrims to use a pilgrimage app, and found effort expectancy, social influence, hedonic motivation as significant factors within the context of pilgrims' travel. The study also finds different sets of crucial predictors for user behaviour.

The previous studies that used UTAUT2 in the context of tourism research, seem to have arrived at differing crucial predictors for explaining tourists behaviour, which warrants further research. At present, there is scarce empirical studies that examined tourists' intentions to use mobile app based accommodation reservation platform, such as the Airbnb for visiting historical cities, which would be useful to explain tourists' behaviour in using digital technology for historical destination tourism.

\subsection{Theory building}

This research applies the UTAUT2 model to examine the behavioural intention of tourists to use the Airbnb app when booking their accommodation in Malacca. The UTAUT2 model was formulated via a review of eight prominent models by Venkatesh et al. (2003), namely "the Theory of Reasoned Action (TRA) (Fishbein and Ajzen 1975)", "the Theory of Planned Behaviour (TPB) (Ajzen 1991)", "the Technology Acceptance Model (TAM) (Davis et al. 1989)", "the Motivational Model (MM) (Davis et al. 1992)", "the model of PC Utilisation (MPCU) (Thompson et al. 1991)", "the Innovation Diffusion Theory (IDT) (Rogers 1962)", "the Social 
Cognitive Theory (SCT) (Bandura 1986)", and "the combined TAM and TPB (TAM-TPB) (Taylor and Todd 1995)".

The original UTAUT model consisted of four constructs/variables that is, "effort expectancy", "facilitating conditions", "performance expectancy", and "social influence". This model has been adapted in numerous studies in the area of information system and technology acceptance. However, the variables in the UTAUT model mainly focused on organisational context and hence, Venkatesh et al. (2012) revised the model to form UTAUT2. The UTAUT2 model extends the theory to the consumer context by including three additional constructs, namely "hedonic motivation", "habit" and "price value". The UTAUT2 is found to have improved the explained variance of "behavioural intention" by $18 \%$ and technology usage by $12 \%$ which allows for a better explanation for users' behavioural intention and technology usage. However, criticism of the UTAUT2 models highlights its complexity and variability. Based on our previous literature critique, we notice the importance of context-specificity in the application of UTAUT2 model to explain user adoption behaviour of a technology.

\subsubsection{Behavioural intention}

The main objective of a systems acceptance model is to study the behavioural intention of users to perform a certain behaviour. Behavioural intention is how likely a person will engage in a given behaviour. As a construct, it was first used in the "Theory of Reasoned Action" (TRA) proposed by Fishbein and Ajzen (1975) and applied in the area of social psychology. The TRA model was developed to study the behavioural intention to perform a given behaviour based on the individual's attitude and subjective norms towards that behaviour (Hung et al. 2014). For example, the TRA model was applied to study the adoption behaviour of Green Information Technology (Mishra et al. 2014). The study found behavioural intention positively affects the actual behaviour of users.

In addition, the Theory of Planned Behaviour (TPB), an extension of the TRA model was developed by Ajzen (1985). The constructs found in TPB model include attitude, subjective norm and perceived behavioural control. "Perceived behavioural control" is defined as "the perceived ease or difficulty of performing the behaviour (Ajzen 1991)". Furthermore, Ajzen (1991) stated that the higher the perceived behavioural control, the more likely an individual would have a stronger intention to perform a given behaviour. Han et al. (2010) applied the TPB model to study customers' intention to visit a green hotel and found that attitude, subjective norm, and perceived behavioural control positively affected customers' intention to stay at a green hotel.

Technology Acceptance Model (TAM) developed by (Davis 1989) has been widely used by information systems researchers to study users' intention to accept information technology. In TAM model, the behavioural intention of an individual to adopt a technology is determined by perceived usefulness and its perceived ease of use. The perceived usefulness and perceived ease of use in TAM are similar to the performance expectancy and effort expectancy respectively in UTAUT model. 
Based on the previous applications as above, this study operationalise the construct behavioural intention to measure tourists' intention to use mobile Airbnb app when selecting and booking accommodation during their visit and stay in Malacca.

\subsubsection{Effort expectancy}

Effort expectancy is explained as how easy it is for consumers to learn a system (Venkatesh et al. 2012). In other words, the easier it is to learn a system, the stronger would be users' intention to adopt that technology. Effort expectancy is identified as among the most crucial factors of behavioural intention to use a technology (Chong 2013; Venkatesh et al. 2012). Previous study also found users perceive touchscreen mobile devices as easier to operate (Chang et al. 2012) as it allows direct control, touch and interaction with the gadgets (Brasel and Gips 2014); which is seen as an apparent benefit credited to Airbnb mobile app as compared to web-based accommodation booking systems.

Consumers are more likely to adopt a system that is effortless to use and trustworthy (Tang et al. 2014; Chaw and Tang 2019). A study of key factors that influence the adoption of mobile wallets among Malaysian Generation Y found that users' intention to use mobile wallets is mostly driven by effort expectancy (Tang et al. 2014). Similar findings were observed for effort expectancy in influencing consumer intention to reuse mobile apps (Fong et al. 2017). Hence, H1 is forwarded for testing as below:

H1: Effort expectancy has a significant positive effect on tourists' behavioural intention to use Airbnb app.

\subsubsection{Hedonic motivation}

Hedonic motivation is a new construct added to the UTAUT2 model. It refers to the enjoyment and pleasure obtained from adopting or using something, in this context a mobile app. Mobile apps seem to have an element of stickiness to it where users tend to check their mobile devices very often for updates and to engage in social media, compared to a computer or laptop. Leong et al. (2013) further posit that people will be willing to adopt and transact with mobile apps if it brings excitement and enjoyment.

The age of users was found to have an impact on their hedonic motivation and behavioural intention in previous works involving UTAUT2 model. A study conducted in the UK to determine users' behavioural intention to adopt mobile payments found the effect of hedonic motivation is stronger for younger men who lacked technology experience (Slade et al. 2013); while Macedo (2017) found hedonic motivation to be indirectly affecting older adults' behavioural intention to adopt technology.

Hedonic motivation exerts a positive impact on the behavioural intention of school teachers to accept learning management software. It was the second most important factor that affected the teachers' behavioural intention (Raman and Don 2013). Baptista and Oliveira (2015) argue hedonic motivation is the most significant 
determinant to influence behavioural intention of users to adopt mobile banking. Hence, $\mathrm{H} 2$ is forwarded for testing as below:

H2: Hedonic motivation has a significant positive effect on tourists' behavioural intention to use Airbnb app.

\subsubsection{Performance expectancy}

Performance expectancy refers to individuals' perception of how using a technology assists them to do their tasks better (Venkatesh et al. 2003). It measures how a particular technology caters to the completion of a task more efficiently. When users of technology are aware that it enables them to accomplish their tasks more efficiently, they will likely adopt the technology even if it requires payment. Performance expectancy of a technology or system is posited to have a positive impact on the behavioural intention of users to use and adopt a technology.

Performance expectancy in the context of this study is the degree to which tourists perceive Airbnb app to facilitate and improve their experience of making accommodation reservations. Fong et al. (2017) found users' intention to reuse mobile apps for hotel reservation is positively impacted by performance expectancy. A recent study conducted in Laos examined factors that affect users' behavioural intention to use mobile learning; the result shows the direct impact of perceived usefulness to users' behavioural intention of using mobile learning (Poong et al. 2017). In another study, Tang et al. (2014), found performance expectancy important in influencing Malaysian Gen Y users' behavioural intention to adopt the usage of mobile wallet.

Taiwo and Downe (2013) argue performance expectancy as the most grounded factor of behavioural intention compared to other variables in the UTAUT2 model. A study by Braun (2013), found 124 older adults aged between 60-90 viewed performance expectancy as a significant predictor of their behavioural intention to use social networking websites. Hence, $\mathrm{H} 3$ is forwarded for testing as below:

H3: Performance expectancy has a significant positive effect on tourists' behavioural intention to use Airbnb app.

\subsubsection{Habit}

Habit is the likelihood of a person to perform a behaviour automatically after learning. It can be explained by the extent to which a person will repeat an action after experiencing it (Venkatesh et al. 2012). Often such habits are unconscious and impromptu as a user repeats it over and over again. Studies indicate that the habitual behaviour of users affects their behavioural intention to adopt mobile social networking services positively (Nikou and Bouwman 2014).

Habit is also found to be the main determinant of users' behavioural intention to post and share their past experiences through social networking sites (Herrero et al. 2017); and in impacting behavioural intention to use a e-learning system in Qatar (El-Masri and Tarhini 2017). 
Recent research conducted in Indonesia found habit as the strongest determinant among Indonesians to use mobile wallet apps (Megadewandanu et al. 2017). Similarly, another study investigating factors that affect travellers' behavioural intention to purchase airline tickets from low-cost carriers' website, with a sample size of 1096 guests found travellers' behavioural intention to purchase flight tickets online is determined by their habit (Escobar-Rodríguez and Carvajal-Trujillo 2014). Similarly, habit is found to affect students' and teachers' behavioural intention to adopt Google Classroom Apps (Jakkaew and Hemrungrote 2017). In this study, habit is defined as the automatic user interaction with the Airbnb app in completing an accommodation booking. Hence, $\mathrm{H} 4$ is forwarded for testing as below:

H4: Habit has a significant positive effect on tourists' behavioural intention to use Airbnb app.

\subsubsection{Social influence}

Social influence is explained as the degree to which an individual perceives that people important to him or her think they should use a system or technology (Venkatesh et al. 2003). It is often explained as peer-influence. A recent study found social influence as the most crucial factor that influenced behavioural intentions of Jordanians to adopt mobile commerce services (Mousa Jaradat and Al Rababaa 2013). Similarly, Chong (2013) found social influence as the most significant factor that affects mobile commerce usage and adoption among vast groups of online consumers in China.

Social influence is also found to be an important factor that affects users' mobile payment adoption (Koenig-Lewis et al. 2015). Oliveira et al. (2016) found social influence had significant direct influence on users' behavioural intention to use and recommend mobile payment technology. Social influence also shows direct positive effect on behavioural intention to reuse mobile apps for hotel reservations (Fong et al. 2017); and to continue using messaging app such as WhatsApp (Bere 2014). Hence, H5 is forwarded for testing as below:

H5: Social influence has a significant positive effect on tourists' behavioural intention to use Airbnb app.

\subsection{Price value}

Price value is the trade-off between perceived benefits consumers obtain and the monetary cost of adopting a system. Price value is added to the UTAUT2 model because the trade-off between cost and benefit gained from using a technology is deemed a crucial predictor of users' behavioural intention (Venkatesh et al. 2012). Price value of using a technology is higher when the cost of using that technology is lower than the benefits gained from it.

A study on mobile banking adoption found price value has a significant positive impact on users' behavioural intention to adopt mobile banking (Alalwan et al. 
2017). Similarly, users' intention to purchase air tickets online is found significantly impacted by price value. (Escobar-Rodríguez and Carvajal-Trujillo 2014). Hence, H6 is forwarded for testing as below:

H6: Price value has a significant positive effect on tourists' behavioural intention to use Airbnb app.

\subsection{Facilitating conditions}

Facilitating conditions refer to the organisational and technical infrastructures available that support technology usage by a group of users, commonly workers in a firm. It also includes the user's ability and skills to use the resources available as part of the infrastructures (Venkatesh et al. 2012). Individuals who have favourable facilitating conditions would show stronger intentions to accept and adopt a technology. Martins et al. (2014), reported facilitating conditions exert a strong positive impact on users' behavioural intention to adopt internet banking.

People unconsciously seek for assistance when they are trying to use a new technology (Lewis et al. 2013), and require seamless assistance when faced with problems of using a technology. A study conducted in Latvia found facilitating conditions as among the most important determinants of users' behavioural intention to adopt mobile internet usage (Fuksa 2013). Likewise, Koenig-Lewis et al. (2015) found facilitating conditions have a significant impact on users' behavioural intention to use mobile payment apps. A user-friendly mobile app should be able to quickly help to resolve users' problems when using the app. The extent to which Airbnb app is able to fulfil this condition is tested in H7, as below:

H7: Facilitating conditions have a significant positive effect on tourists' behavioural intention to use Airbnb app.

The 7 hypotheses above are forwarded for testing in this research. Additionally, gender and age of respondents are also tested for their moderation effect with tourists' behavioural intention to use Airbnb app as found in the original UTAUT2 model.

\subsection{Age and gender moderation}

The UTAUT2 model is also exhaustive in measuring the moderating impact of users' demographics. Previous studies investigating apps adoptions, found users' gender and age groups influenced their behavioural intentions (Guttentag and Smith 2017; Lutz and Newlands 2018; Amaro et al. 2019). To investigate this further, this study performs a moderation analysis of gender and age groups of tourists and their behavioural intentions to use the Airbnb app.

Figure 1 shows the research framework of this study. 


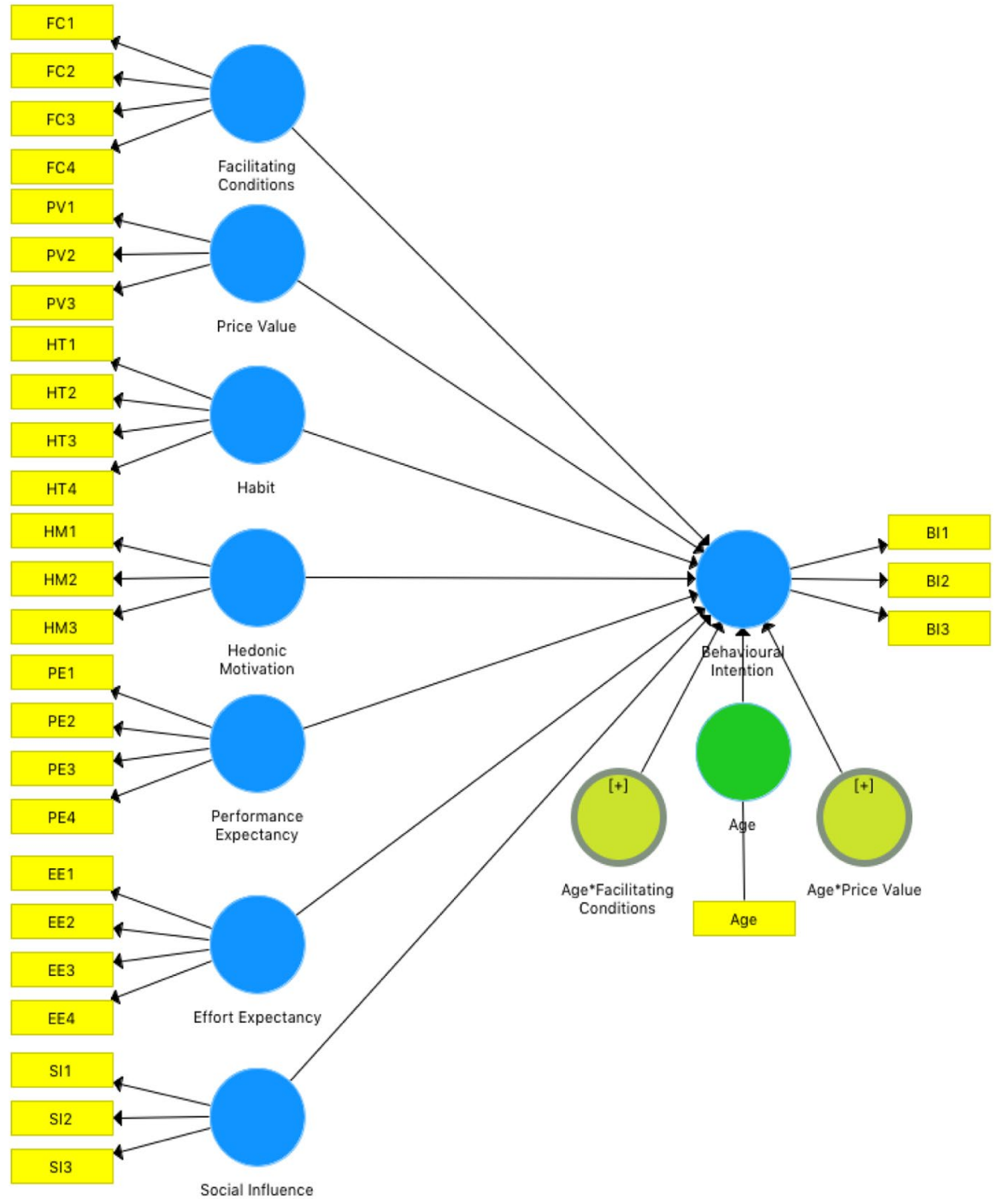

Fig. 1 Research framework

\section{Research methodology}

This study gathered research data from tourists who have visited and stayed in Malacca and used the Airbnb mobile app to book their accommodation in Malacca. To estimate an accurate sample size for data collection, GPower software was used (GPower 2017). The minimum sample size required for a study of this nature is determined as 153 samples, based on the effect size of 0.25 and the statistical power of 0.95 . To ensure adequate data collection beyond the required minimum, the researchers conducted 200 face to face interviews with tourists in Malacca, using 
quota sampling technique in order to have equal representation of both male and female tourists to allow for gender moderation analysis. All field works and interviews for data collection were done in the heart of the historical city of Malacca between January 2018 to July 2018. All tourists who participated in this research were approached at the historical attractions in the city, such as the A'Famosa Portuguese Fort, St. Pauls' Hills, St. John's Hills, the Stadhuys and Jonker Street Malacca; locations that have the Dutch, Portuguese and British heritage histories to them.

A structured research questionnaire comprising of demographic questions and statements to measure each research variables was used for quantitative data collection. Each construct in the UTAUT2 model was measured using the constructs originally developed by Venkatesh et al (2012) with items adapted to the context of tourism and the usage of Airbnb (see Table 2). A total of 25 items were used to measure all seven independent variables and 3 items to measure the dependent variable. A 6-point Likert scale was used and the items were modified and adapted to measure tourists' intention to use the Airbnb app when visiting a historical city. A 6-point Likert scale instead of the usual 5-point scale was used as cross cultural studies using a 6-point scale offers advantages including less response biases and yields more reliable responses, as compared to the 5 point and 7 point likert scales (Dolincar et al. 2011; Chomeya 2010).

Data analysis for descriptive statistics was conducted using SPSS software version 24, while hypotheses testing and path-modelling was built using Partial Least Square (PLS) Structured Equation Modelling (SEM) using SmartPLS version 3.0. Although both Co-variance based SEM (CB-SEM) and PLS-SEM are widely used in social sciences, in this research we selected PLS-SEM over CB-SEM, driven by aim not to discard any indicators to achieve acceptable goodness-of-fit, rather identify crucial factors that have significantly highest and lowest impacts on tourists' intention to use Airbnb App when booking their stay at a historical city. As this study pioneers the application of UTAUT2 to test users' adoption of Airbnb App, we modified all indicators from the original UTAUT2 items to make them relevant to the current context (Table 2). Given these conditions, PLS-SEM is believed to be robust in testing new indicators and assessing the overall model composite reliability and convergent validity (Hair et al. 2017).

\section{Results and discussions}

This section presents research data analysis, descriptive statistics followed by empirical results.

\subsection{Descriptive statistics}

Table 1 displays respondents' demographic characteristics.

Equal participation was received from both male and female respondents; 100 samples each respectively through quota sampling. A higher percentage of the respondents are between $25-34$ years old, which is about $42.5 \%$ (85 persons), most 
Table 1 Respondents' demographic Information

\begin{tabular}{lrl}
\hline Demographics & Frequency & Percentage \\
\hline Gender & & \\
Male & 100 & 50 \\
Female & 100 & 50 \\
Age & & \\
18 to 24 & 73 & 36.5 \\
25 to 34 & 85 & 42.5 \\
35 to 44 & 23 & 11.5 \\
45 to 54 & 18 & 9.0 \\
55 or older & 1 & 0.5 \\
Relationship status & & \\
Single & 107 & 53.5 \\
Married & 93 & 46.5 \\
Reason for travelling & & \\
For pleasure/holiday & 200 & 100.0 \\
For business & 0 & 0 \\
Travelling partners & & \\
$\quad$ Alone & 3 & 1.5 \\
With family members & 102 & 47.5 \\
With friends & 95 & \\
\hline & &
\end{tabular}

likely due to tech-savviness of young adults as compared to the older tourists in adopting mobile apps. Everyone who participated in this study visited Malacca for pleasure and was on holiday. It is observed that $98.5 \%$ of respondents use the internet on a daily basis and have all had previous experience using the Airbnb app.

\subsection{Normality and reliability of research items}

Table 2 displays the items used in the research questionnaire. Data normality analysis indicates all research variables are normally distributed, with Skewness and Kurtosis within the range of + or -2 . Reliability analysis results based on Cronbach Alpha values show all values above the acceptance threshold of 0.7 .

\subsection{Assessment of measurement model}

The measurement model was assessed to ensure construct validity, convergent validity, and discriminant validity. Composite reliability, Average Variance Extracted and Factor loadings were used to confirm the convergent validity of the proposed model (see Fig. 1). Composite reliability values higher than 0.7 are acceptable. However, composite reliability values above 0.95 are not desirable. Composite reliability values above 0.95 could indicate the presence of semantically redundant items in a construct. Since redundant items may adversely impact the content validity and error term correlations, it is recommended to minimise the number of redundant items 
Table 2 Research item statistics

Constructs (in bold) and items

Effort expectancy

Learning how to use Airbnb app is easy for me

My interaction with Airbnb app is clear and understandable

I find Airbnb app easy to use

It is easy for me to become skillful at using Airbnb app

\section{Hedonic motivation}

Using Airbnb app is fun

Using Airbnb app is enjoyable

Using Airbnb app is very entertaining

\section{Performance expectancy}

I find Airbnb app useful in my daily life

Using Airbnb app increases my chances of achieving things that are important to me

Using Airbnb app helps me accomplish things more quickly

Using Airbnb app increases my productivity

\section{Habit}

The use of Airbnb app has become a habit for me

I am addicted to using Airbnb app

I must use Airbnb app

Using Airbnb app has become natural to me

\section{Social influence}

People who are important to me think that I should use Airbnb app

People who influence my behaviour think that I should use Airbnb app

People whose opinions that I value prefer that I use Airbnb app

Price value

Airbnb is reasonably priced

Airbnb is a good value for the money

At the current price, Airbnb provides a good value

\section{Facilitating condition}

I have the resources necessary to use Airbnb app

I have the knowledge necessary to use Airbnb app

Airbnb app is compatible with other technologies I use

I can get help from others when I have difficulties using Airbnb app

\section{Behavioural intention}

I intend to continue using Airbnb app in the future

I will always try to use Airbnb app in my daily life

I plan to continue to use Airbnb app

Skewness Kurtosis Cronbach alpha

$\begin{array}{lll}-0.257 & -0.153 & 0.798\end{array}$

$\begin{array}{lll}-0.093 & -0.102 & 0.835\end{array}$

$\begin{array}{lll}-0.088 & -0.398 & 0.751\end{array}$

$\begin{array}{lll}0.077 & -0.694 & 0.873\end{array}$

$\begin{array}{lll}-0.227 & 0.123 & 0.873\end{array}$

$\begin{array}{lll}-0.335 & -0.39 & 0.816\end{array}$

$\begin{array}{lll}-0.157 & -0.308 & 0.799\end{array}$

$\begin{array}{lll}-0.202 & 0.093 & 0.817\end{array}$


(Hair et al. 2017). Average variance extracted values higher than 0.5 and factor loadings above 0.50 are required to confirm the convergent validity of a model (Chin 1998). AVE values of 0.5 and above indicate that the constructs are able to explain more than $50 \%$ of the variance of its indicators.

Construct validity implies the strength of results obtained from the use of measure fit the theories around which the test is designed (Sekaran and Bougie 2010). Internal consistency reliability can be confirmed with a threshold value of 0.70 for the loadings (Hair et al. 2014).

All items in this study have loadings above 0.70 except for two items in the constructs, performance expectancy and effort expectancy. The two items have a loading of 0.682 and 0.681 respectively. Since the values are very close to 0.70 and meet the fit criteria as suggested by Hair et al (2016), they are not removed from the model. The Average Variance Extracted of the constructs are well above 0.50 which implies that the constructs capture more than half of the variance of its indicators. The composite reliability values of the constructs lie above 0.80 . Three constructs namely Habit, Hedonic Motivation, and Social Influence have values above 0.90 . However, the values did not exceed the critical threshold of 0.95 hence retained. Thus, construct validity and convergent validity of the model is established. Table 3 summarises the results.

Fornell and Larcker technique was used to assess discriminant validity of the constructs. The proposed model satisfies the discriminant validity criterion if the square root of AVE of each construct is more than the correlation between the items (Fornell and Larcker 1981). The square roots of AVEs shown diagonally in boldface are higher than the other values given in Table 4. Based on this result, discriminant validity criterion is met for all research variables.

\subsection{Assessment of structural model}

Hair et al. (2014) proposed a five step procedure which includes the assessment of collinearity (VIF), coefficient of determination $\left(R^{2}\right)$, predictive relevance $\left(Q^{2}\right)$, effect size $f^{2}$, and path coefficients to assess the validity of a structural model.

Table 3 Factor loadings, average variance extracted and composite reliability

\begin{tabular}{lllll}
\hline Constructs & Measurement items & Loading range & $\begin{array}{l}\text { Composite } \\
\text { reliability }\end{array}$ & $\begin{array}{l}\text { Average vari- } \\
\text { ance extracted }\end{array}$ \\
\hline Facilitating conditions & FC1,FC2,FC3,FC4 & $0.744-0.842$ & 0.869 & 0.624 \\
Price value & PV1,PV2,PV3 & $0.807-0.889$ & 0.891 & 0.731 \\
Habit & HT1,HT2,HT3,HT4 & $0.821-0.885$ & 0.912 & 0.721 \\
Hedonic motivation & HM1,HM2,HM3 & $0.840-0.892$ & 0.901 & 0.751 \\
Performance expectancy & PE1,PE2,PE3,PE4 & $0.682-0.822$ & 0.844 & 0.576 \\
Effort expectancy & EE1,EE2,EE3,EE4 & $0.681-0.883$ & 0.891 & 0.731 \\
Social influence & SI1,SI2,SI3 & $0.875-0.914$ & 0.922 & 0.798 \\
Behavioural intention & BI1, BI2, BI3 & $0.810-0.893$ & 0.893 & 0.737 \\
\hline
\end{tabular}




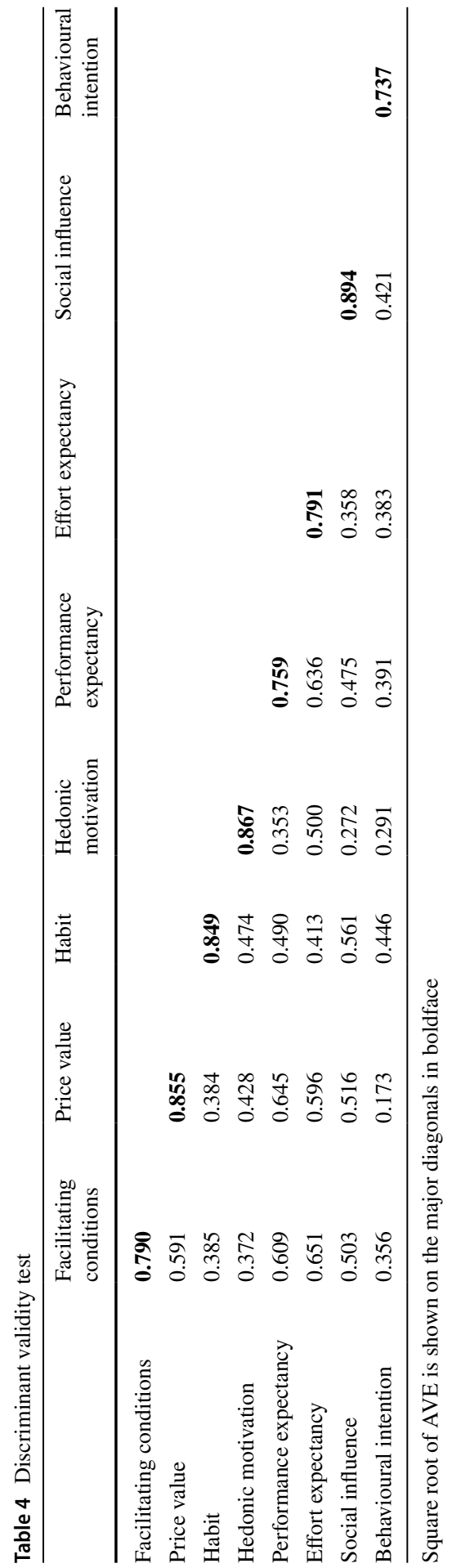


The Variance Influence Factors (VIF) assess the collinearity among the indicators. Multicollinearity exists if the correlations between the independent variables are too high. Even if discriminant validity is confirmed, the strong causal effects may give wrong results (Kock and Lynn 2012). The threshold value for VIF recommended by (Hair et al. 2014) is below 5. The VIF values for this model are below 3 .

The overall $R^{2}$ of the model is 0.673 and the adjusted $R^{2}$ is 0.65 . The $R$ square value implies $67 \%$ of total variance in the dependent variable (tourists' behavioural intention to use Airbnb app) can be explained by the 7 independent research variables. The value is above 0.35 as recommended by (Cohen 1988), which affirms model significance. The $Q$ squared coefficient shows the predictive capacity of the structural model and values above is 0 is acceptable (Hair et al. 2016). The PLS Path Model with coefficient values of loading can be observed in Fig. 2.

The relationship between the variables was further analysed by applying the bootstrapping technique in SmartPLS with 5000 subsamples to test the research hypotheses formulated. Table 5 summarises the hypotheses test results.

The results show effort expectancy, performance expectancy, social influence, and price value have a significant positive influence on tourists' behavioural intention to use Airbnb app when visiting Malacca. Hence H1, H3, H5, H6, and H7 are supported. This finding is in agreement with previous works that have asserted the importance of users' effort expectancy, system performance expectancy, social influence and price value to adopt an app (Gupta and Dogra 2017; Chopdar et al. 2018; Alalwan et al. 2017).

Among these significant factors, price value has relatively the highest impact on tourists' usage of Airbnb app (beta $=0.581$ ). Price value is potentially the first driver for app users to use Airbnb app. When tourists search for accommodations using usual hotel web listings and encounter high prices, they often resort to Airbnb app, seeking for better price value. This suggests that tourists who use Airbnb while visiting historical cities are price sensitive in making accommodation reservations. This finding is in agreement with earlier works that reported exorbitant prices for accommodations at historical destinations (Caserta and Russo 2002; Lee and Chhabra 2015), and further suggests Airbnb app as a potential game changer in the tourism of historical cities, where accommodations are made more affordable for tourists.

Social Influence is the second highest predictor towards tourists' use of Airbnb app (beta $=0.289$ ), indicating a strong influence of how tourists feel about people around them and their peer-approval when using Airbnb app. This finding corroborates with previous works that highlighted the impact of social influence on the adoption of mobile apps for hotel reservations (Fong et al. 2017).

This study finds the two major predictors for tourists' intention to use Airbnb app for accommodation booking at a historical city are Price Value and Social Influence, unlike the earlier works that examined UTUAT2 model in tourism where performance expectancy and hedonic motivation were found more crucial (Min and $\mathrm{Lu}$ 2017; Gupta and Dogra 2017). This shows that within the field of mobile App adoption and tourism, there could be different sets of behavioural predictors for tourists' behaviours with regards to the context of the study. In this study, it is context-specific to historical destination tourism. 


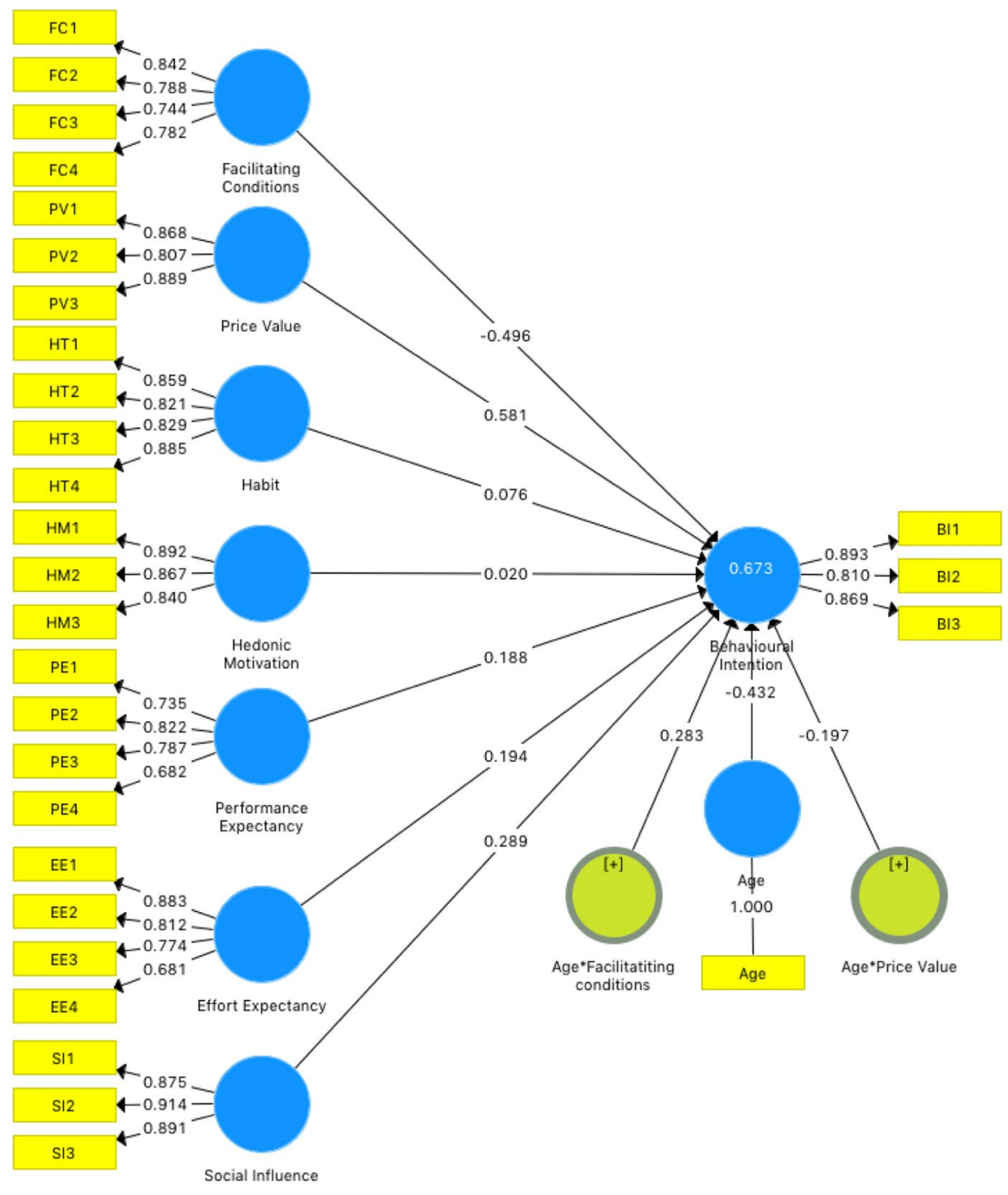

Fig. 2 PLS Path model with coefficients

Effort expectancy and performance expectancy have an almost similar impact on tourists' use of Airbnb app with beta values of 0.194 and 0.188 respectively. Both these factors are found important in previous works, however, performance expectancy is usually the most important factor in predicting user adoption of a technology (Venkatesh et al. 2012), but found to be less important in explaining tourists' use of Airbnb app. This finding suggests a subtle difference between technology adoption in general versus the adoption of a mobile app for tourism. Moreover, compared to the earlier works carried out since a decade ago on the adoption of systems that were mostly web-based; mobile apps are built on a much more user-adaptive 
Table 5 Hypotheses test results

\begin{tabular}{|c|c|c|c|c|c|}
\hline Hypotheses & Relationship & $\begin{array}{l}\text { Std } \\
\text { Beta }\end{array}$ & Bootstrap $t$-values & Decision & $f^{2}$ \\
\hline $\mathrm{H} 1$ & $\begin{array}{l}\text { Effort expectancy behavioural inten- } \\
\text { tions }\end{array}$ & 0.194 & $3.084 *$ & Supported & 0.047 \\
\hline $\mathrm{H} 2$ & $\begin{array}{l}\text { Hedonic motivation behavioural } \\
\text { intentions }\end{array}$ & 0.02 & 0.39 & Not supported & 0.009 \\
\hline $\mathrm{H} 3$ & $\begin{array}{l}\text { Performance expectancy behavioural } \\
\text { intentions }\end{array}$ & 0.188 & $3.071 *$ & Supported & 0.045 \\
\hline $\mathrm{H} 4$ & Habit behavioural intentions & 0.076 & 1.351 & Not supported & 0.001 \\
\hline H5 & $\begin{array}{l}\text { Social influence behavioural inten- } \\
\text { tions }\end{array}$ & 0.289 & $4.422 * *$ & Supported & 0.134 \\
\hline H6 & Price value behavioural intentions & 0.581 & $2.485 *$ & Supported & 0.045 \\
\hline $\mathrm{H} 7$ & $\begin{array}{l}\text { Facilitating conditions behavioural } \\
\text { intentions }\end{array}$ & -0.496 & $2.320 *$ & Supported & 0.034 \\
\hline
\end{tabular}

${ }^{*} P<0.05 ; * * P<0.001$

platform that is highly intuitive for users to use and adopt; which makes effort and performance expectancy not as crucial as they were in the early days of IT systems and technology adoption. This finding hence calls for a reassessment of the UTAUT2 model, where some predictors such as effort expectancy and performance expectancy may not be relevant predictors for users' adoption of new digital technologies such as mobile Apps.

The findings of this study also reveal hedonic motivation and habit do not significantly predict tourists' behavioural intention to use Airbnb app, although previous works have found them significant. A probable explanation for this result could be the nature of these two factors in the context of adopting a P2P app such as Airbnb. Both hedonic motivation and habit were previously used to measure repeated enjoyment behaviour, which was found to be necessary for measuring usage of apps such as mobile banking and e-learning systems that are used repeatedly over a close period of time. This is unlike the way most tourists use Airbnb app, it is used less frequently (as compared to mobile banking app for example) and usually only during the traveling period. Hence, this study finds Airbnb adoption and usage can't be explained by hedonic motivation and habit, suggesting platform based mobile apps such as the Airbnb app does not lead to continuous habit forming. Similarly, a recent study conducted in Brazil using UTAUT2 to analyze tourists' intention to adopt Airbnb found hedonic motivation not significant in predicting behavioural intention (Christino et al. 2019).

Facilitating condition is the only construct in this study that shows a significant negative influence on tourists' behavioural intentions to use Airbnb app. This peculiar result is not altogether new in the study of systems adoption and the theory behind UTAUT2 (Venkatesh et al. 2011). Although facilitating conditions are originally meant to measure the impact of users' belief that there is help available in the system should they need it; perhaps in the context of a mobile app, this is perceived as counter-productive. Mobile App users who are IT savvy, coupled with Airbnb 
app that is designed with functional and aesthetic usability do not require technical support to operate the app. On the contrary, the potential disruption of system assistance that tries to help a user who does not need help may appear as an inhibitor to use the app. Based on dissonance theory (Festinger 1957), it can be explained that, if facilitating condition is perceived by users as an inhibitor to their use of an app, users would possibly adjust their attitudes negatively to remain consistent with their situation (Venkatesh et al. 2011). This could explain the significant negative impact of facilitating conditions to tourists' use of Airbnb app. Additionally, this result is moderated by tourists' age, as discussed below.

The result of moderation analysis reveals that the age of tourists significantly moderates behavioural intentions to use Airbnb app, particularly moderating the impact of facilitating conditions and price value towards behavioural intentions. Using $f^{2}$ statistics helps in identifying the substantive significance of this moderating impact with the magnitude of effect size (Henseler et al. 2009). A rule of thumb as suggested by (Cohen 1988), for $f^{2}$ values consider 0.02 as having small effect, 0.15 medium effect and 0.35 as having large moderating effect. The $f^{2}$ values as given in Table 6 for the significant constructs.

Upon performing the bootstrapping test, age of respondents shows significant positive moderating effect on facilitating conditions; Age*FC, with path coefficient $\beta=0.283, t=3.357, p<0.05$. This is an insightful finding as facilitating conditions was found earlier in the hypotheses testing as the only construct with a negative impact on tourists' behavioural intention to use Airbnb app. Coupled with this positive moderation result, it indicates that as the age of tourists increases, the impact of facilitating conditions to their behavioural intention is less negative. In other words, older tourists see facilitating conditions as more positive compared to younger tourists when using Airbnb app. This suggests that older tourists who use Airbnb app would require more help with the app (and they appreciate it) while younger tourists do not seek help to use the app. Unlike the findings of Macedo (2017) who found hedonic motivation to be indirectly affecting older adults' behavioural intention to adopt technology, this study finds no significant impact of hedonic motivation towards older adults' use of Airbnb app, instead, we find facilitating conditions as a more important predictor for this segment.

The moderation effect of tourists' age on price value; Age*PV, reveals significant negative relationship with behavioural intention, path coefficient $\beta=-0.197$ $t=2.304, p<0.05$, indicating as the age of tourists increases, price value's impact towards their behavioural intention to use Airbnb app diminishes. This result suggests that older tourists are not driven by price value as much as younger tourists when using Airbnb app. Younger tourists are motivated largely by price value to use

Table 6 Moderation effect analysis

\begin{tabular}{lrll}
\hline Relationship & Std beta & Bootstrap $t$-values & $f^{2}$ \\
\hline Age*FC & 0.283 & $3.357^{*}$ & 0.068 \\
Age*PV & -0.197 & $2.304^{*}$ & 0.035 \\
\hline${ }^{*} P<0.05$ & & &
\end{tabular}


Airbnb app, as opposed to older tourists. Older tourists are found not as price sensitive when visiting a historical city, and perhaps they are motivated to experience a historical city differently with higher luxury intent than the younger more price-sensitive tourists. Contrary to previous work of Braun (2013), who found older adults viewed performance expectancy as a highly significant predictor of their behavioural intention to use social networking websites, in this study we find performance expectancy having very minimal predictive effect towards tourists' behavioural intention to use Airbnb app, instead we find facilitating conditions have positive relationship with age, while price value have negative relationship with age, towards tourists' behavioural intention to use Airbnb app.

\subsection{Importance performance matrix analysis}

A post-hoc Importance Performance Matrix Analysis (IPMA) was conducted using behavioural intentions as the target outcome variable. The aim of IPMA is to analyse the model to identify the predecessors that have relatively high significance with regard to the target construct (Ringle and Sarstedt 2016). The IPMA extends the results obtained from the PLS SEM by considering the performance of each construct separately. The results of Importance Performance Matrix Analysis are suggested as an important evaluation for studies involving technology acceptance, customer satisfaction and corporate reputation (Ringle and Sarstedt 2016). Figure 3 shows the Importance-Performance map for this research model.

From Fig. 3, performance of each variable is indicated by the values given on the $\mathrm{Y}$ axis and its corresponding importance in the study as total effects on $\mathrm{X}$ axis. Based on this result, price value has the strongest influence on behavioural intentions with a performance value of 55.64 and a total effect of 0.546 . Although the performance of effort expectancy, performance expectancy and social influence are high $(57.42,61.54,53.29)$, their influence on the dependent variable

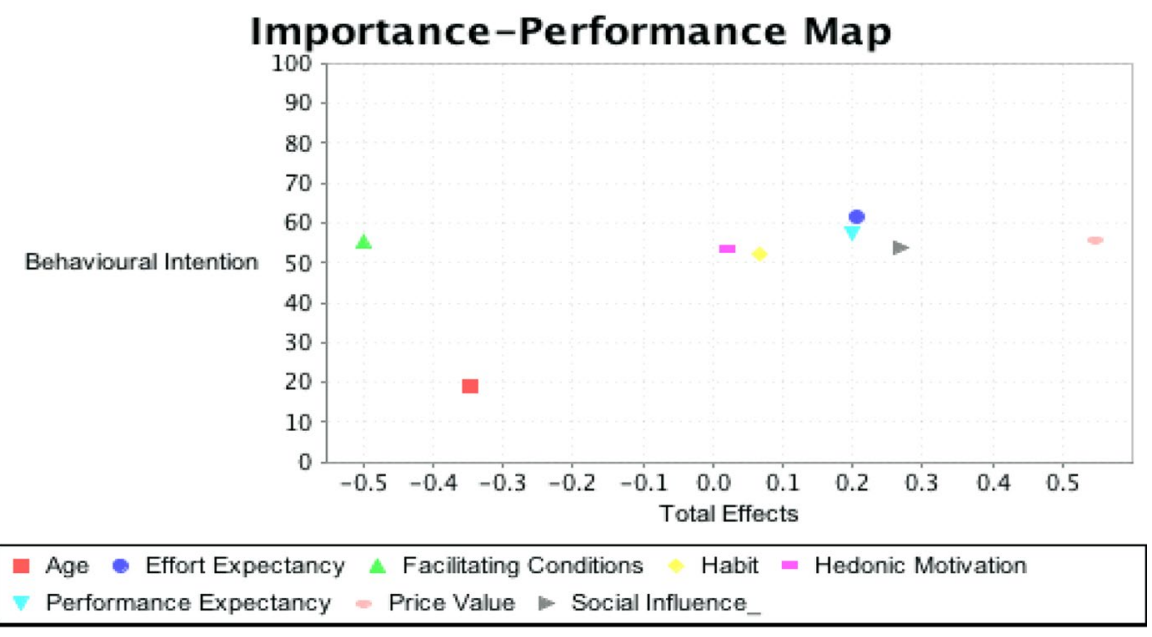

Fig. 3 Importance-performance map for the model 
is moderate $(0.19,0.20,0.26)$. On the other hand, facilitating conditions has a strong negative impact on behavioural intention with performance value of 55.17 and the impact on behavioural intentions is -0.55 . The total effects of habit and hedonic motivation on behavioural intention are close to zero, signalling little relevance in predicting tourists' use of Airbnb app.

\section{Conclusion}

This research adopted the UTAUT2 model to study the factors affecting tourists' behavioural intention to use Airbnb app when visiting the historical city of Malacca in Malaysia, an emerging economy. Based on results and findings of the study, price value is found as the largest predictor for tourists' behavioural intention to use Airbnb app; followed by social influence, performance expectancy and effort expectancy. This affirms the impact of value-based pricing that aids tourists' decision making when selecting accommodations at a heritage city like Malacca.

The amalgamation of digital technologies and platform based app like Airbnb in the tourism ecosystem has made it more accessible and affordable for tourists to book their accommodations. This, in turn, has brought a large number of tourists to visit historical cities like Malacca which were previously accessible to more affluent tourists and boosted the local economic growth.

Hedonic motivation and habit are found to have no direct influence on tourists' behavioural intention to use Airbnb app. This is believed due to the lack of continuous and repeated use of mobile travelling apps like the Airbnb app, compared to apps that are repeatedly used where enjoyment is developed over the period of repeated use. We find travelling apps like Airbnb app are non-habit forming.

Facilitating conditions on the other hand reveal a significant negative effect on behavioural intention, which we believe is due to the IT savvy nature of predominantly younger app users who rely less on system helps to perform tasks in an app, and we find this 'unneeded help' as counter-productive for young tourists in using a mobile travelling app.

This study finds no evidence of gender impact on tourists' use of Airbnb app, however age groups show significant moderating effect on price value and facilitating conditions towards behavioural intention to use Airbnb.

The findings of this study validate some constructs in the UTAUT2 theory to explain tourists behavioural intention to use a mobile app, namely price value and social influence are found to be the largest predictors. Subsequently, this study raises new questions on the relevance of some constructs in the theory that lack predictive power in explaining user behaviour in adopting mobile app for tourists. The UTAUT2 model was effective in previous works in measuring users' systems and technology adoption behaviour, however this study finds that the theory may not be adequate to predict users' adoption of a mobile app. We find performance expectancy, effort expectancy, hedonic motivation and habit as lacking predictive power in explaining tourists' use of Airbnb app. 


\section{Limitations and suggestions for future study}

This study analysed tourists' accommodations booking behaviour using a P2P Airbnb mobile app when visiting and staying in the historical city of Malacca. Research data collection was done using a survey questionnaire administered to 200 tourists who visited and stayed in Malacca and had experience using the Airbnb app. We were unable to capture the location of origin and nationality of the tourists who participated in this study, as the motivation of the study was to investigate the potential moderating role of gender and age. Knowing their country-of-origin, or cultural background would have aided in understanding their travel motivations better.

This research examined the behavioural intention of tourists to use Airbnb app based on the UTAUT2 model, while it did not include the construct use behaviour in the measurement model. Future studies could extend this work by capturing both the country-of-origin of tourists and also their use behaviour for mobile travel apps for tourism. Since facilitating condition is found negatively impacting behavioural intention in this study, future studies could further validate this finding by measuring this construct in the use of other similar platform-based app.

Although we used quota sampling and collected 100 responses from male and female tourists respectively, data analysis finds no gender effect towards behavioural intention. Age group is a significant moderator instead, however age groups in this study were not equally represented. Future studies could focus on the impact of age groups to the use of mobile travel apps by having equal representations of age groups.

Previous research findings have indicated the impact of $\mathrm{P} 2 \mathrm{P}$ economy platform to other related industries. Zhang et al. (2018) found the exit of Uber and Lyft from Austin in the United States in May 2016 led to a decrease of 9.6\% in Airbnb property demand. This indicates an inter-dependency among platform-based businesses. Future studies could investigate these interactions closely for the historical city tourism and tourism industry in general, for instance, the impact of ride-sharing app demand such as Grab and its impact on Airbnb app and vice versa.

Acknowledgements Open access funding provided by Szent István University (SZIE).

Open Access This article is licensed under a Creative Commons Attribution 4.0 International License, which permits use, sharing, adaptation, distribution and reproduction in any medium or format, as long as you give appropriate credit to the original author(s) and the source, provide a link to the Creative Commons licence, and indicate if changes were made. The images or other third party material in this article are included in the article's Creative Commons licence, unless indicated otherwise in a credit line to the material. If material is not included in the article's Creative Commons licence and your intended use is not permitted by statutory regulation or exceeds the permitted use, you will need to obtain permission directly from the copyright holder. To view a copy of this licence, visit http://creativecommons.org/licen ses/by/4.0/.

\section{References}

Ajzen I (1991) The theory of planned behaviour. Organ Behav Hum Decis Process 50:179-211 
Alalwan AA, Dwivedi YK, Rana NP (2017) Factors influencing adoption of mobile banking by Jordanian bank customers: Extending UTAUT2 with trust. Int J Inf Manag 37(3):99-110

Amaro S, Andreu L, Huang S (2019) Millenials' intentions to book on Airbnb. Curr Issues Tour 22(18):2284-2298

Amir S, Osman MM, Bachok S, Ibrahim M (2015) Sustaining local community economy through tourism: Melaka UNESCO world heritage city. Proc Environ Sci 28:443-452

Antunes A, Amaro S (2016) Pilgrims' acceptance of a mobile app for the Camino de Santiago, Information and Communication Technologies in Tourism. Springer, Cham, pp 509-521

Baptista G, Oliveira T (2015) Understanding mobile banking: the unified theory of acceptance and use of technology combined with cultural moderators. Comput Hum Behav 50:418-430

Bardhi F, Eckhardt GM (2012) Access based consumption: the case of car sharing. J Consum Res 39(4):881-898

Bere A (2014) Exploring determinants for mobile learning user acceptance and use: an app of UTAUT. 11th International Conference on Information Technology: New Generations, 84-90

Brasel SA, Gips J (2014) Tablets, touchscreens, and touchpads: how varying touch interfaces trigger psychological ownership and endowment. J Consum Psychol 24(2):226-233

Braun MT (2013) Obstacles to social networking website use among older adults. Comput Hum Behav 29(3):673-680. https://doi.org/10.1016/j.chb.2012.12.004

Byers J, Proserpio D, Zervas G (2016) The rise of the sharing economy: estimating the impact of airbnb on the hotel industry. SSRN Electron J 13:1-36. https://doi.org/10.2139/ssrn.2366898

Caserta S, Russo AP (2002) More means worse: asymmetric information, spatial displacement and sustainable heritage tourism. J Cult Econ 26(4):245-260

Chang TY, Tsai CJ, Lin JH (2012) A graphical-based password keystroke dynamic authentication system for touch screen handheld mobile devices. J Syst Softw 85(5):1157-1165. https://doi.org/10.1016/j. jss.2011.12.044

Chaw LY, Tang CM (2019) Online accommodation booking: what information matters the most to users? Inf Technol Tour, 1-22

Chomeya R (2010) Quality of psychology test between Likert scale 5 and 6 points. J Soc Sci 6(3):399-403

Chong AYL (2013) Predicting m-commerce adoption determinants: a neural network approach. Expert Syst Apps 40(2):523-530. https://doi.org/10.1016/j.eswa.2012.07.068

Chopdar PK, Korfiatis N, Sivakumar VJ, Lytras MD (2018) Mobile shopping apps adoption and perceived risks: a cross-country perspective utilizing the unified theory of acceptance and use of technology. Comput Hum Behav 86:109-128

Christino JMM, Silva TS, Cardozo EAA, Lopes AGR (2019) Adoption of online shared hosting platforms: a study of Users' behavior of the airbnb system. Revista Turismo. https://doi.org/10.14210/ Rtva.V21n1.P165-185

Davis F (1989) Perceived usefulness, perceived ease of use, and user acceptance of information technology. MIS Quart 13(3):319-340. https://doi.org/10.1016/S0305-0483(98)00028-0

Davis FD, Bagozzi RP, Warshaw PR (1992) Extrinsic and intrinsic motivation to use computers in the workplace. J Appl Soc Psychol 22(14):1111-1132. https://doi.org/10.1111/j.1559-1816.1992.tb009 45.x

Davis FD, Bagozzi RP, Washaw PR (1989) User acceptance of computer technology: a comparison of two theoretical models. Manag Sci 35(September):982-1003

Dolnicar S, Grun B, Leisch F, Rossiter J (2011) Three good reasons NOT to use five and seven point Likert items.

El-Masri M, Tarhini A (2017) Factors affecting the adoption of e-learning systems in Qatar and USA: extending the unified theory of acceptance and use of technology 2 (UTAUT2). Educ Tech Res Dev. https://doi.org/10.1007/s11423-016-9508-8

Escobar-Rodríguez T, Carvajal-Trujillo E (2014) Online purchasing tickets for low cost carriers: an app of the unified theory of acceptance and use of technology (UTAUT) model. Tour Manag 43:70-88. https://doi.org/10.1016/j.tourman.2014.01.017

Fishbein M, Ajzen I (1975) Belief, attitude, intention, and behavior: an introduction to theory and research. Addison-Wesley Publishing Company, Reading, MA

Fong LHN, Lam LW, Law R (2017) How locus of control shapes intention to reuse mobile apps for making hotel reservations: evidence from Chinese consumers. Tourism Manag 61:331-342. https://doi. org/10.1016/j.tourman.2017.03.002

Foo R, Krishnapillai G (2018) Preserving the tangible living heritage in the George Town World Heritage Site Malaysia. J Herit Tour. https://doi.org/10.1080/1743873X.2018.1549054 
Fuksa M (2013) Mobile technologies and services development impact on mobile internet usage in Latvia. Proc Comput Sci 26:41-50. https://doi.org/10.1016/j.procs.2013.12.006

Goh SL, Koh C, Nathan RJ (2012) Service quality dimensions and tourist satisfaction towards Melaka hotels. Int J Econ Manag Eng 2(1):26-32

GPower (2017) No title. Retrieved from https://www.gpower.hhu.de/en.html Accessed on 11 March 2019

Gupta A, Dogra N (2017) Tourist adoption of mapping apps: a UTAUT2 perspective of smart travellers. Tour Hospit Manag 23(2):145-161

Guttentag D (2015) Airbnb: disruptive innovation and the rise of an informal tourism accommodation sector. Curr Issues Tour 18(12):1192-1217. https://doi.org/10.1080/13683500.2013.827159

Guttentag DA, Smith SL (2017) Assessing Airbnb as a disruptive innovation relative to hotels: substitution and comparative performance expectations. Int J Hospit Manag 64:1-10

Hair JF Jr, Sarstedt M, Hopkins L, Kuppelwieser G (2014) Partial least squares structural equation modeling (PLS-SEM) An emerging tool in business research. Eur Bus Rev 26(2):106-121

Hair Jr, J. F., Hult, G. T. M., Ringle, C., \& Sarstedt, M. (2016). A primer on partial least squares structural equation modeling (PLS-SEM). Sage publications.

Hair JF, Matthews LM, Matthews RL, Sarstedt M (2017) PLS-SEM or CB-SEM: updated guidelines on which method to use. Int J Multivariat Data Anal (IJMDA), Vol. 1, No. 2. Inderscience.

Han H, Hsu LT, Sheu C (2010) App of the theory of planned behavior to green hotel choice: testing the effect of environmental friendly activities. Tourism Manag 31(3):325-334. https://doi.org/10.1016/j.tourm an.2009.03.013

Henseler J, Ringle CM, Sinkovics RR (2009) The use of partial least squares path modeling in international marketing. In New challenges to international marketing (pp. 277-319). Emerald Group Publishing Limited.

Herrero A, San Martin H, Garcia-De los Salmones M (2017) Explaining the adoption of social networks sites for sharing user-generated content: a revision of the UTAUT2. Comput Hum Behav 71:209-217. https ://doi.org/10.1016/j.chb.2017.02.007

Hung S-Y, Tsai JC-A, Chuang C-C (2014) Investigating primary health care nurses' intention to use information technology: an empirical study in Taiwan. Decis Support Syst 57(1):331-342. https://doi. org/10.1016/j.dss.2013.09.016

Jakkaew P, Hemrungrote S (2017) The use of UTAUT2 model for understanding student perceptions using google classroom: a case study of introduction to information technology course.

Jansen-Verbeke M (1998) Tourismification of historical cities. Ann Tourism Res 25(3):739-742

Koenig-Lewis N, Marquet M, Palmer A, Zhao AL (2015) Enjoyment and social influence: predicting mobile payment adoption. Serv Ind J 35(10):537-554. https://doi.org/10.1080/02642069.2015.1043278

Lee W, Chhabra D (2015) Heritage hotels and historic lodging: Perspectives on experiential marketing and sustainable culture. J Heritage Tourism 10(2):103-110

Leong LY, Ooi KB, Chong AYL, Lin B (2013) Modeling the stimulators of the behavioral intention to use mobile entertainment: does gender really matter? Comput Hum Behav 29(5):2109-2121. https://doi. org/10.1016/j.chb.2013.04.004

Lewis CC, Fretwell CE, Ryan J, Parham JB (2013) Faculty use of established and emerging technologies in higher education: a unified theory of acceptance and use of technology perspective. Int J Higher Educ 2(2):22-34. https://doi.org/10.5430/ijhe.v2n2p22

Lutz C, Newlands G (2018) Consumer segmentation within the sharing economy: the case of Airbnb. J Bus Res 88:187-196

Macedo IM (2017) Predicting the acceptance and use of information and communication technology by older adults: an empirical examination of the revised UTAUT2. Comput Hum Behav. https://doi. org/10.1016/j.chb.2017.06.013

Martins C, Oliveira T, Popovič A (2014) Understanding the Internet banking adoption: a unified theory of acceptance and use of technology and perceived risk app. Int J Inf Manag 34(1):1-13

Megadewandanu S, Suyoto A, Pranowo A (2017) Exploring mobile wallet adoption in Indonesia using UTAUT2: an approach from consumer perspective. Proceedings-2016 2nd International Conference on Science and Technology-Computer, ICST 2016, 11-16. https://doi.org/10.1109/ICSTC.2016.78773 40

Min W, Lu L (2017) Who wants to live like a local?: An analysis of determinants of consumers' intention to choose AirBNB. In 2017 International Conference on Management Science and Engineering (ICMSE) (pp. 642-651). IEEE.

Mishra D, Akman I, Mishra A (2014) Theory of reasoned action app for green information technology acceptance. Comput Hum Behav 36:29-40. https://doi.org/10.1016/j.chb.2014.03.030 
Mousa Jaradat M-IR, Al Rababaa MS (2013) Assessing key factor that influence on the acceptance of mobile commerce based on modified UTAUT. Int J Bus Manag 8(23):102-112. https://doi.org/10.5539/ijbm. v8n23p102

Mutal SS (2011) The future of historic cities: a practitioner's experience. Hist Environ 23(1):61

Nikou S, Bouwman H (2014) Ubiquitous use of mobile social network services. Telematics Inform 31(3):422-433. https://doi.org/10.1016/j.tele.2013.11.002

Oliveira T, Thomas M, Baptista G, Campos F (2016) Mobile payment: Understanding the determinants of customer adoption and intention to recommend the technology. Comput Hum Behav 61(2016):404414. https://doi.org/10.1016/j.chb.2016.03.030

Perez-Sanchez VR, Serrano-Estrada L, Marti P, Mora-Garcia RT (2018) The what, where, and why of Airbnb price determinants. Sustainability 10(12):4596

Pizam A (2014) Peer-to-peer travel: Blessing or blight? International Journal of Hospitality Management 38:118-119. https://doi.org/10.1016/j.ijhm.2014.02.013

Poong YS, Yamaguchi S, Takada J-I (2017) Investigating the drivers of mobile learning acceptance among young adults in the World Heritage town of Luang Prabang. Laos Inf Dev 33(1):57-71. https://doi. org/10.1177/0266666916638136

Raman A, Don Y (2013) Preservice teachers' acceptance of learning management software: an app of the UTAUT2 model. Int Educ Stud 6(7):157-164. https://doi.org/10.5539/ies.v6n7p157

Rents and Returns (2018) Airbnb in Malaysia: from a property investors point of view. Rents and returns, https://blog.rentandreturns.com/airbnb-in-malaysia-property-investors-point-of-view/. Accessed on 15 Oct 2019

Ringle CM, Sarstedt M (2016) Gain more insight from your PLS-SEM results: the importance performance map analysis. Ind Manag Data Syst 116(9):1865-1886

See G, Goh Y (2018) Tourists' intention to visit heritage hotels at george town world heritage site. J Herit Tourism 14(1):33-48

Slade E, Williams M, Dwivdei Y (2013) Extending UTAUT2 to explore consumer adoption of mobile payments. UK Academy for Information Systems Conference Proceedings, 23. Retrieved from https://aisel .aisnet.org/ukais2013/36/

Taiwo AA, Downe AG (2013) The theory of user acceptance and use of technology (Utaut): a meta-analytic review of empirical findings, 49(1).

Tang CY, Lai CC, Law CW, Liew MC, Phua VV (2014) Examining key determinants of mobile wallet adoption intention in Malaysia: an empirical study using the unified theory of acceptance and use of technology 2 model. International Journal of Modelling in Operations Management, 4(3), 248-265. Retrieved from https://www.inderscienceonline.com/doi/abs/10.1504/IJMOM.2014.067383?journalCode=ijmom

Taylor S, Todd P (1995) Assessing IT usage: the role of prior experience. MIS Quart 19(4):561. https://doi. org/10.2307/249633

Teo CBC, Khan NRM, Rahim FHA (2014) Understanding cultural heritage visitor behavior: the case of melaka as world heritage city. Proc Soc Behav Sci 130(0):1-10. https://doi.org/http://dx.doi.org/10.1016/j. sbspro.2014.04.001

Tham A (2016) When harry met sally: different approaches towards Uber and AirBnB — an Australian and Singapore perspective. Inf Technol Tourism 16(4):393-412

Thestar Online (2018) https://www.thestar.com.my/metro/metro-news/2018/02/01/more-tourists-visit-melak a-number-of-visitors-the-highest-seen-by-state-in-years/ Accessed on 26 Feb 2019

Thompson RL, Higgins CA, Howell JM (1991) Personal computing: toward a conceptual model of utilization. MIS Quart 15(1):125. https://doi.org/10.2307/249443

Venkatesh V, Morris MG, Davis GB, Davis FD (2003) User acceptance of information technology: toward a unified view. MIS Quart 27(3):425-478. https://doi.org/10.2307/30036540

Venkatesh V, Thong JY, Chan FK, Hu PJH, Brown SA (2011) Extending the two-stage information systems continuance model: incorporating UTAUT predictors and the role of context. Inform Syst J 21(6):527-555

Venkatesh V, Thong JYL, Xu X (2012) Consumer acceptance and use of information technology: extending the unified theory. MIS Quart 36(1):157-178. https://doi.org/10.1017/CBO9781107415324.004

Yoon S (2017) Transitions of trust across different business context: impact of the sharing economy on the lodging industry, (May). Retrieved from https://www.unlv.edu/system/files/file_attachments_private/ Dissertation_SungsikYoon.pdf

Zhang S, Lee D, Singh PV, Mukhopadhyay T (2018) Demand Interactions in Sharing Economies: Evidence from a Natural Experiment Involving Airbnb and Uber/Lyft. Tepper School of Business, 
Carnegie Mellon University. Available at SSRN: https://ssrn.com/abstract=3124712 or https://dx.doi. org/10.2139/ssrn.3124712

Publisher's Note Springer Nature remains neutral with regard to jurisdictional claims in published maps and institutional affiliations.

\section{Affiliations}

\section{Robert Jeyakumar Nathan $^{1}$ (D) Vijay Victor $^{2}$ D $\cdot$ Melanie $\operatorname{Tan}^{1}$ (D) Maria Fekete-Farkas ${ }^{3}$}

Robert Jeyakumar Nathan

robert.jeyakumar@mmu.edu.my

Vijay Victor

Victor.Vijay@phd.uni-szie.hu

Melanie Tan

melanietpy@gmail.com

1 Faculty of Business, Multimedia University, 75450 Malacca, Malaysia

2 Doctoral School of Management and Business Administration, Szent Istvan University, Godollo 2100, Hungary

3 Faculty of Economics and Social Sciences, Szent Istvan University, Godollo 2100, Hungary 